\title{
INDIRECT ECONOMIC IMPACT OF RURAL INFRASTRUCTURE SUPPORT OF RDP 2007-2013 IN POLAND AND LATVIA
}

\author{
Agnieszka Wojewodzka-Wiewiorska ${ }^{1}$, Juris Hazners ${ }^{2}$, Agnese Krievina ${ }^{2}$ \\ ${ }^{1}$ Warsaw University of Life Sciences, Poland; \\ ${ }^{2}$ Institute of Agricultural Resources and Economics, Latvia \\ agnieszka_wojewodzka@sggw.pl,juris.hazners@arei.lv, agnese.krievina@arei.lv
}

\begin{abstract}
The evaluation of the EU co-funded programmes is gaining an increased importance in recent years, and the main question to be answered is whether the policy intervention has resulted in achieving the objectives that have been set. While the evaluation process usually is focused on direct effects of the programme with the assessment of specific result indicators, the estimation of indirect, unintended effects is also important. The purpose of the article is to evaluate the indirect economic impact of the rural infrastructure support of the RDP 2007-2013 on rural areas in Poland and Latvia by exploring the implementation of the Measure 321 in each of the countries and by evaluating the impact of the measure on tax revenues in the supported rural areas of Poland and Latvia. The main challenge in the evaluation of indirect effects, especially, if municipalities are supported, is the lack of the counterfactual, and, in this case, generalized propensity score matching (GPSM) method has its advantages over the binary propensity score matching (PSM) method. Therefore, the existing study provides a comparative assessment using the GPSM method. The average treatment effect on treated units is calculated using the changes in tax revenues per capita over the programme period as a dependent variable. A number of economic, financial and social pretreatment variables for rural territorial units were selected as independent covariates for matching. The research results show a strong positive indirect effect of the support on the changes in tax revenues in supported rural territorial units in both countries.
\end{abstract}

Keywords: policy evaluation, RDP 2007-2013, GPSM method, indirect effects.

\section{Introduction}

The rural areas in Poland have been facing such main problems as no job vacancies, migrations by work (pendulum), poorly developed technical and social infrastructure in rural areas (regional diversity), poorly developed network of services for people in rural areas, low level of social capital, as well as depopulation of peripheral areas $[1 ; 2]$. Similar problems can be observed also in the rural areas of Latvia, furthermore, the population density in the territory outside the capital Riga and its adjacent region is only 18 inhabitants per $\mathrm{km}^{2}$; and the decrease in the number of population there has been by about $25 \%$ since 2000 [3]. Therefore, it is a challenging task to develop the rural area as an attractive living and working space, for which all local resources and potential for the growth are to be used [4].

One of the main tools for solving the problems of rural areas are the EU funds within the respective programmes, including the Rural Development Programme (RDP). In the programming period 2007-2013, the total amount of 17,432.6 million EUR of public support was provided by the RDP in Poland, and 1,366 million EUR of public money was used for the RDP in Latvia [5; 6].

Considering a notable amount of the EU public money spent on the rural development measures, the evaluation of the EU co-funded programmes is gaining an increased importance in recent years as it serves to provide the knowledge on the effects of this expenditure. Showing of the policy achievements, thus justifying the support for rural development measures, is considered important at European and regional levels, especially under limited budgets. Findings of the evaluation provide an indispensable input for the policy makers, being a major source of policy learning [7].

The main question to be answered in the programme evaluation is whether the policy intervention has resulted in achieving the objectives that have been set. While the evaluation process is usually focused on direct effects of the programme with the assessment of specific result indicators, other effects of the programme independent intervening factors should be addressed as well. In policy interventions, programme direct economic effects affect the supported beneficiaries in an immediate way as a direct result of the programme support, and the evaluation of the direct programme effects is performed at the level of direct programme beneficiaries (individuals or municipalities/communities). However, various result indicators that are utilised as relevant outcomes for individual beneficiaries such as economic growth and the number of jobs created not always are applicable when municipalities are concerned. At a municipality level, estimation of the programme indirect effects 
that spread throughout the economy are more appropriate. For example, changes in municipality tax revenues show an indirect programme effect on overall economic welfare.

The purpose of the article is to evaluate the indirect economic impact of the rural infrastructure support of the RDP 2007-2013 on rural areas in Poland and Latvia. To achieve that, the specific tasks for the study have been set 1) to explore the implementation of Measure 321 (Basic services for the economy and rural population) of the RDP 2007-2013 in Poland and Latvia; and 2) to evaluate the impact of Measure 321 of the RDP 2007-2013 on tax revenues in the supported rural areas of Poland and Latvia.

Poland and Latvia may differ by economic and geographic size, population density in rural areas, rural infrastructure etc. Nevertheless, netting out the indirect effect of the programme support would allow for a comparison in terms of the programme contributions on per capita basis.

\section{Materials and methods}

In the evaluation of the programme impact, the lack of randomness in the programme support allocation is considered the main obstacle in identifying a causal relationship between treatment (i.e., support) and outcome. In the context of RDPs, factors like population density, number of farms and rural businesses, quality of infrastructure, level of welfare and other regional and community characteristics can affect the direction and amount of the support. The commonly used propensity score matching (PSM), first introduced by Rosenbaum and Rubin [8], is the method, which restores the randomness. The method uses binary treatment variable and compares the observable characteristics of units to screen out a control group that to the largest extent resembles the treated group. The method was further extended into categorical multivalued treatment by Imbens [9], while the generalized propensity score matching (GPSM) using continuous treatment variable was proposed by Hirano and Imbens [10]. A significant issue associated with the evaluation of the policy intervention impact applying the binary PSM method is the non-availability of a control group in a situation where all territorial units receive a programme support; and usually, if implemented, most rural territorial units are eligible for community support Measure 321 of RDPs. However, if a continuous variable is introduced (like support per capita by a territorial unit) a GPSM methodology is especially advantageous and therefore used in the study.

The steps to be taken in the evaluation of the RDPs with the GPSM method are specified in the evaluation guidelines elaborated by Michalek [11], he applied this approach in the estimation of the impact of the SAPARD programme in Slovakia [12]; and this study follows the introduced methodology. To assess the contribution of public policies, the GPS has also been applied in the studies by Bia and Mattei [13] and Kluve et. al [14].

Generally, for a sample of rural territorial units $(i=1, \ldots, N)$, there is a set of outcomes $Y i(t)$ corresponding to a given treatment $t \in T$ (amount or level of programme support). In the binary case, the treatment would be $t \in\{0,1\}$; while in the case of GPSM the treatment is continuous, with the interval $\left[t_{0}, t_{1}\right]$, with $t_{0}>0$ (this is not true if a number of territorial units haven't received support). In the present study, for each rural territorial unit $i$ there is an outcome (changes in tax revenues) corresponding to a given programme intensity level (per capita support $(T)$ of Measure 321 ) and a vector of regional covariates $\left(X=a_{1}, \ldots, a_{n}\right)$. The basic objective of the performed analysis was to estimate the average dose-response function $\mu(t)$ and the derivative of the dose-response function $v(t)$. The dose-response function helps answer the question, whether the programme support induces growth in tax revenues, as it shows the average effect of the support in relation to the support intensity:

$$
\mu(t)=E\left[Y_{i}(t)\right],
$$

where $Y_{i}-$ value of the outcome variable (per capita tax revenue);

$t$ - programme support level.

While the derivative dose-response function shows the marginal effects of the support, in relation to the support intensity [11].

To eliminate bias stemming from the differences in territorial unit covariates, there is a necessity for the adjusting of the Generalized Propensity Score (GPS) as it has a balancing property similar to 
the balancing property of the propensity score for binary treatments $[10 ; 11]$. For the needs of the present study, the GPS of territorial units was calculated as a conditional density of treatment $(T)$, based on the covariates characterizing the territorial units $\left(a_{1}-a_{n}\right)$, while the parameters of the treatment function were assessed applying maximum likelihood. The conditional treatment function was calculated as

$$
L n_{-} t \mid X_{i} \approx N\left(\beta_{0}+\beta_{1}^{\prime} X_{i}, \sigma^{2}\right),
$$

where $X$ - vector of covariates $\left(a_{1}-a_{n}\right)$;

$L n \_t-\operatorname{logarithm}$ of support intensity per capita.

The obtained estimates were used to get the territorial unit specific propensity scores (prior to the support implementation):

$$
\hat{R}_{i}=\frac{1}{\sqrt{2 \pi \sigma^{2}}} \exp \left[-\frac{1}{2 \hat{\sigma}^{2}}\left\{g\left(T_{i}\right)-h\left(\hat{\gamma}, X_{i}\right)\right\}\right],
$$

where $X$ - vector of covariates $\left(a_{1}-a_{n}\right)$;

$T i$ - programme support level.

Further, the test of the balancing properties of the covariates developed by Hirano and Imbens [10] was performed by blocking on the treatment variables (support intensity per capita) and on the obtained GPS. While the balancing property test (t-test) introduced by Bia and Mattei [13] was carried out for all variables $a_{1}-a_{n}$ in pre-specified blocks of GPS (in our study, two) and programme intensity levels (in our study, three) by testing if for each GPS block the covariate means of territorial units attributed to the group of the particular level of the support intensity vary significantly from the territorial units with a different level of the support intensity, but a similar GPS level.

The conditional expectation for the analysed outcome that is expressed as the changes in tax revenues, $Y=\Delta T \cdot G P S$, was computed as a flexible polynomial quadratic function with two arguments:

$$
Y=b_{0}+b_{1} T+b_{2} T^{2}+b_{3} G P S+b_{4} G P S^{2}+b_{5} T * G P S,
$$

where $T i$-programme support level;

$G P S$ - estimated generalized propensity scores.

For the implementation of the calculations, data panels were created for Poland and Latvia enclosing continuous treatment variable $\mathrm{T}$ (per capita programme support for Measure 321), outcome variable Y (changes in tax revenues per capita between 2009 and 2014) and a set of independent variables prior to the programme. The base year 2009 was used instead of 2007 due to the data constraints as the result of the administrative reform in Latvia. Independent variables include both continuous variables (population, employment, finance, economics etc.) and binary variables (presence of railway, location on a border or a sea coast etc.). For Poland and Latvia, 29 and 40, respectively, independent pre-treatment variables were selected depending on the availability of information. Data panels for Poland and Latvia contained information on 314 and 108 territorial units (i.e., aggregated data for districts in Poland and data for municipalities in Latvia), respectively. For Latvia, programme per capita support, changes in tax revenues and other financial variables were expressed in euros, while for Poland values in Polish zlotys (PLN) were used.

Detailed data were made available for the purposes of the study by the Ministry of Agriculture and Rural Development as at 31 Dec 2015 [5] and data from the Central Statistical Office [15] in Poland. Data from the Regional Development Indicator Module [16], Central Statistical Bureau of Latvia [3], as well as unpublished data of Rural Support Service (RSS) [17] have been used for the municipalities in Latvia.

\section{Results and discussion}

1. Implementation of the Measure 321

In the programming period 2007-2013, Poland and Latvia were among the countries, which in their RDPs chose to implement Measure 321 - Basic services for the economy and rural population. In Poland, EUR 1,814 million from public money were spent on this measure, which constituted $10.5 \%$ 
of total RDP 2007-2013 funds, while in Latvia public funding for Measure 321 was EUR 89.1 million, accounting for $6.5 \%$ of its total RDP spending [5; 6].

The general rationale for the introduction of the measure was to avert the negative economic and social trends (including depopulation) in European countryside by supporting basic services for the economy and rural population, and by this aiming to sustain and improve the living conditions and the attractiveness of the area [18].

The implemented activities within the measure in each of the country are depicted in Fig. 1.

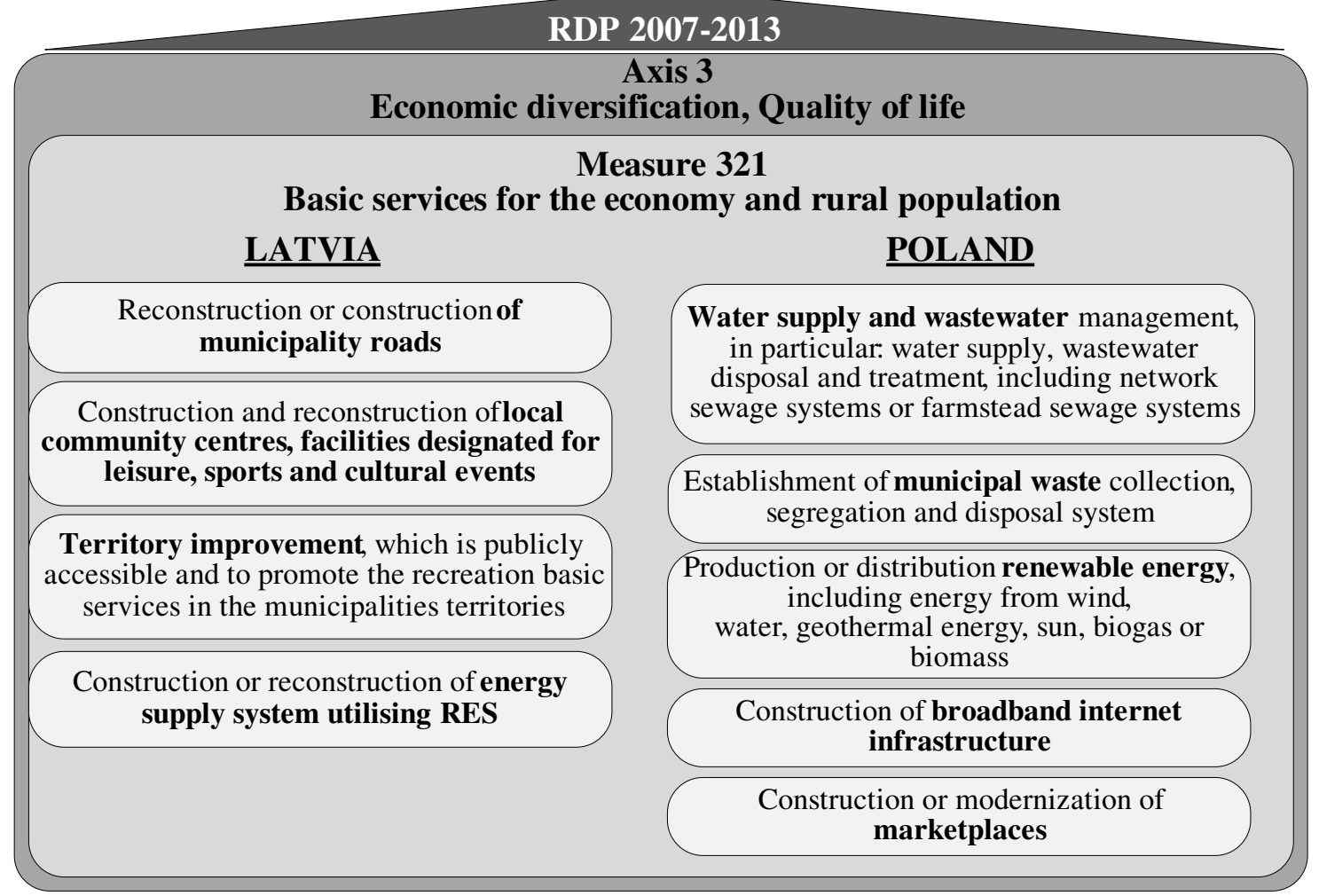

Fig. 1. Implemented actions within Measure 321 of RDP 2007-2013 in Poland and Latvia [1; 19]

As it can be seen from Fig. 1, the countries chose different activities for the implementation as the means to enhance the quality of life in their rural area, with the only overlapping activity relating to the energy supply systems utilising renewable energy sources (RES). In Latvia, the projects implemented under this activity covered municipality centralized heat supply systems, as well as heat supply systems in municipality public buildings. However, this was a comparatively small activity in Latvia, with 34 projects implemented and the public support of EUR 2.7 million spent in total, which was only about $3 \%$ of the total public support for the measure [6;17]. While more than half $(55 \%)$ of the total public funding of Measure 321 went to the activity supporting local community centres and leisure, sports and cultural facilities, followed by the activity aimed at municipality roads (35\%) [17].

In Poland, projects related to RES included the purchase of solar and wind energy installations (mainly street lighting), installation of solar batteries or investments in boiler rooms using biomass in public utility buildings, most often schools. These projects received support in the amount of 23.5 million EUR, which also accounted only for $1.3 \%$ of the total Measure 321 funding [20]. While the activities implemented under Measure 321 were dominated by projects related to the construction of sewerage networks, water supply systems and the construction or purchase of infrastructure related to municipal waste management, in total 1730 million EUR were spent on projects in this field. The percentage of projects related to the construction of Internet infrastructure and modernization of marketplaces was small, as only 11 Internet projects and 235 projects concerning marketplaces were carried out, which accounted for $0.07 \%$ and $3.3 \%$ of the Measure 321 funding, respectively.

The various activities were chosen by the countries, considering the specific interests and needs of the rural areas of Poland and Latvia, but with a common goal - to improve the rural infrastructure to maintain rural population. In this respect, the evaluation of the indirect economic impact of the 
Measure 321 in each of the countries has been presented further, using GPSM method. RDP 20142020 assumes further support for the development of rural infrastructure. In Poland, the importance of building or modernizing local roads, investments in facilities that perform cultural functions and protection of monuments is now underlined. In Latvia, the focus has been put on improving the quality of municipality roads that can support the entrepreneurial activities in the rural area.

2. Indirect economic impact of the Measure 321

By applying the log transformation function, with covariates $\left(a_{1}-a_{n}\right)$ as function arguments and per capita support per territorial unit as dependent variable, the conditional distribution of support per capita intensity (treatment function) under territorial unit specific covariates was estimated for Poland and Latvia. Further, in order to implement the balancing property tests, the range of the programme support intensity (set of the potential treatment values) was divided into three treatment intervals. While the values of the generalized propensity score evaluated at the representative point of each treatment interval were divided into two intervals (two groups of territorial units).

For Poland, the treatment intervals were established as follows: territorial units with per capita support less than 453 PLN (PLN = 4.2615 EUR as at 31, December 2015, according to the Polish National Bank), from 453 PLN to 659 PLN and over 659 PLN. For Latvia, the intervals were established as follows: territorial units with per capita support less than 98 EUR, from 98 EUR to 139 EUR and over 139 EUR. The results of the balancing tests, which were performed for each covariate and each mean treatment interval, revealed that the covariates in two groups of territorial units were not significantly different, as the balancing property was satisfied for all variables, GPS blocks and intensity levels at a level lower than 0.01 .

Table 1

Obtained parameters of the conditional expectation for the outcome of Measure 321 in Poland

\begin{tabular}{|c|c|c|c|c|c|c|}
\hline \multirow{3}{*}{$\begin{array}{c}\Delta \text { Taxes } \\
(2009- \\
\text { 2014) }\end{array}$} & $\begin{array}{c}\text { Number of } \\
\text { observations }\end{array}$ & $F(5,308)$ & Prob $>F$ & $\begin{array}{c}R- \\
\text { squared }\end{array}$ & $\begin{array}{c}\text { Adj } R- \\
\text { squared }\end{array}$ & Root MSE \\
\hline & 314 & 7.02 & 0.000 & 0.102 & 0.088 & 187.22 \\
\hline & Coef. & Std. Err. & $t$ & $P>|t|$ & \multicolumn{2}{|c|}{$95 \%$ Conf. Interval } \\
\hline $\mathrm{t}$ & 0.51 & 0.29 & 1.78 & 0.08 & -0.06 & 1.08 \\
\hline $\mathrm{t} \_s q$ & -0.00 & 0.00 & -1.57 & 0.12 & -0.00 & 0.00 \\
\hline pscore & -332.39 & 192.31 & -1.73 & 0.09 & -710.79 & 46.01 \\
\hline pscore_sq & 340.15 & 147.34 & 2.31 & 0.02 & 50.24 & 630.06 \\
\hline t_pscore & -0.54 & 0.17 & -3.24 & 0.00 & -0.87 & -0.211 \\
\hline cons & 354.32 & 79.72 & 4.44 & 0.00 & 197.46 & 511.18 \\
\hline
\end{tabular}

Table 2

Obtained parameters of the conditional expectation for the outcome of Measure 321 in Latvia

\begin{tabular}{|c|c|c|c|c|c|c|}
\hline \multirow{3}{*}{$\begin{array}{c}\Delta \text { Taxes } \\
(2009- \\
2014)\end{array}$} & $\begin{array}{c}\text { Number of } \\
\text { observations }\end{array}$ & $F(5,308)$ & Prob $>F$ & $\begin{array}{c}R- \\
\text { squared }\end{array}$ & $\begin{array}{c}\text { Adj } R- \\
\text { squared }\end{array}$ & Root MSE \\
\hline & 106 & 15.7 & 0.000 & 0.440 & 0.412 & 154.48 \\
\hline & Coef. & Std. Err. & $t$ & $P>|t|$ & \multicolumn{2}{|c|}{$95 \%$ Conf. Interval } \\
\hline $\mathrm{t}$ & -3.42 & 0.94 & -3.63 & 0.00 & -5.29 & -1.55 \\
\hline t_sq & 0.02 & 0.00 & 4.20 & 0.00 & 0.01 & 0.02 \\
\hline pscore & -87.22 & 323.80 & -0.27 & 0.79 & -729.63 & 555.19 \\
\hline pscore_sq & 198.04 & 370.42 & 0.53 & 0.59 & -536.85 & 932.94 \\
\hline t_pscore & -3.10 & 1.41 & -2.20 & 0.03 & -5.90 & -0.30 \\
\hline _cons & 723.61 & 80.24 & 9.02 & 0.00 & 564.41 & 882.80 \\
\hline
\end{tabular}

The results of the estimation using equation (3), with the outcome variable representing the change in tax revenues and other variables of relevance are shown in Table 1 and 2.

Considering the calculated individual conditional expectations for the outcome at the territorial unit support intensity levels, the equation (4) was used to obtain the entire dose-response function (DRF) for the average potential outcome for each level of the treatment. While for the marginal causal 
effects, the derivative dose-response function $E[Y(T+1)-Y(T)]$ was used. Standard errors were assessed using bootstrapping methods, which include the estimation of GPS and parameters of the estimated conditional expectation function.

A graphical presentation of the calculation results is shown in Fig. 2.
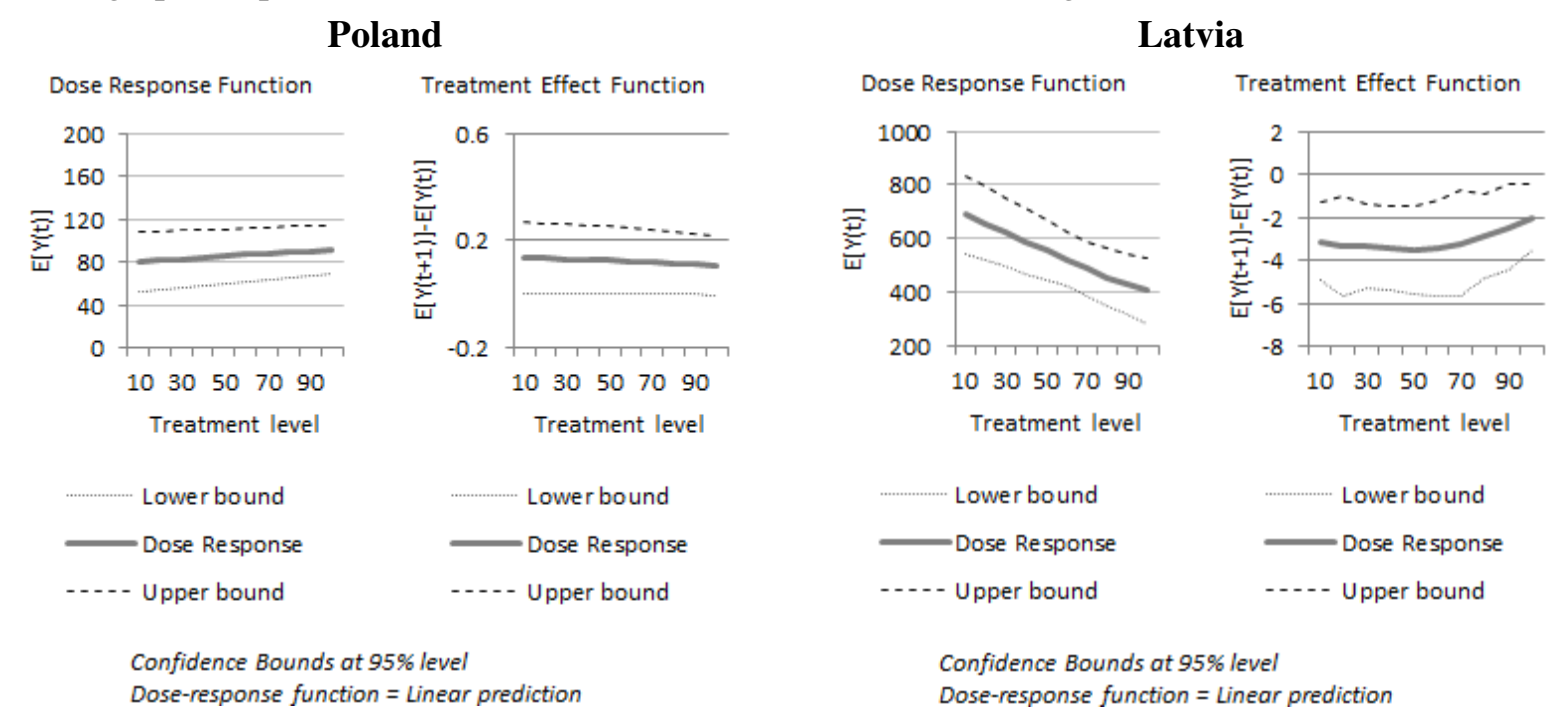

Fig. 2. Obtained dose response function and treatment effect function of impact of Measure 321 on changes in tax revenues (criterion: per territorial unit) in Poland and Latvia in 2009-2014

The estimated impact of the support of the Measure 321 on changes in tax revenues per capita in both countries is strong and positive, even exceeding the real growth of the respective variable. The average treatment effect on treated (ATT), which is calculated as a simple average from DRF function in all intervals, stands at 534 PLN per capita in Poland and at 86 EUR per capita in Latvia. This leads to a conclusion that in the absence of the Measure 321 changes in the tax revenues in both countries would be negative. At a first glance, such impact would seem overestimated. However, in a number of territorial units in both countries the amount of support of the Measure 321 is rather large, if compared to tax revenues, which, essentially, form a territorial unit total budget.

At the same time, the calculations show a difference between Poland and Latvia in the level of the impact of the Measure 321 based on the intensity of the support per capita among territorial units in each country. In Poland, the impact increases by higher per capita support of the Measure 321, while in Latvia there is a decreasing impact of the support by higher support intensity.

\section{Conclusions}

1. In both, Poland and Latvia, the RDP 2007-2013 supported the development of rural infrastructure, but the directions of spending funds varied. In Poland, the largest financial support under the Measure 321 was allocated to water, sewage and waste management, while in Latvia the most funds were directed to local cultural centers, sports and recreation facilities, and municipal roads.

2. Generally, the results of the GPS and dose response function indicate on a positive effect of the rural infrastructure support on the changes in tax revenues in supported rural areas in both countries.

3. While the obtained dose response function reveals a plausible link between the support of the Measure 321 and the growth of the tax revenues, the estimated $95 \%$ confidence intervals are rather broad irrespective to intensity of per capita support. It points to an uncertainty, and the obtained results should be interpreted with precaution.

4. In Latvia, the impact of the infrastructure support reduces rather markedly by the per capita amount. This shows the higher importance of the support being directed towards the "poorer" rural territorial units in terms of per capita amount of the support. In Poland, the opposite is true, albeit less markedly. The impact of the support slowly grows by the per capita amount. Thus, the larger per capita support works supposedly "better". 


\section{References}

[1] Rural Development Programme for 2007-2013 (RDP). Ministry of Agriculture and Rural Development in Poland. Warsaw, 2007.

[2] Rural Poland. The Report on the State of Rural Areas. Ed. Wilkin J., Nurzyńska I., Scholar Publishing House, Warsaw, 2016.

[3] Central Statistical Bureau of Latvia (CSB). Public database. [online] [08.02.2018]. Available at: http://www.csb.gov.lv/dati/statistikas-datubazes-28270.html

[4] Krievina A., Leimane I., Melece L. Analysis of Economic Aspects of LEADER Projects in Latvia. Proceedings of the International Scientific Conference "Economic Science for Rural Development", No 39, April 23-24, 2015, Jelgava, Latvia, pp. 164-175.

[5] Ministry of Agriculture and Rural Development in Poland (MARD). 2017a. Data of the Agency for Restructuring and Modernization of Agriculture concerning the implementation of projects under the 3rd axis of the Rural Development Programme 2007-2013 from 31.Dec 2015.

[6] AREI. Lauku attīstības programmas 2007-2013 Ex-post novērtējums (Ex-post evaluation of RDP 2007-2013) (in Latvian). [online] [12.02.2018]. Available at: http://www.arei.lv/sites/arei/files/files/lapas/LAP \%202007-2013\%20expost \%20nov \%C4 \%93rt \%C4 \%93jums.pdf

[7] European Evaluation Network for Rural Development. Capturing the Success of your RDP: Guidelines for the Ex-post Evaluation of 2007-2013 RDPs. [online] [07.02.2018]. Available at: https://ec.europa.eu/agriculture/sites/agriculture/files/evaluation/guidelines/2007-2013-expost_en.pdf

[8] Rosenbaum P. R., Rubin D. B. The central role of the propensity score in observational studies for causal effects." Biometrika, 1983, 70(1), pp. 41-55

[9] Imbens G. W. The role of the propensity score in estimating dose-response functions. Biometrika 83, 2000, pp. 706-710.

[10] Hirano K., Imbens G. The Propensity score with continuous treatment, chapter for Missing data and Bayesian Method in Practice: Contributions by Donald Rubin Statistical Family, 2004.

[11] Michalek J. Counterfactual impact evaluation of EU Rural Development Programmes Propensity Score Matching methodology applied to selected EU Member States, Volume 2: A regional approach. European Commission, Joint Research Centre, Institute for Prospective Technological Studies, 2012.

[12] Michalek J. Application of the Rural Development Index to evaluation of the impact of SAPARD programme in Poland and Slovakia. Paper at international workshop on "Evaluation and Modelling of Rural Development Policies: Theory and Application”, Kiel 13-14 July, 2009.

[13] Bia M., Mattei A. Application of the Generalized Propensity Score. Evaluation of public contributions to Piedmont enterprises. P.O.L.I.S. department's Working Papers 80, Department of Public Policy and Public Choice - POLIS, 2007.

[14] Kluve et. al. Before and After the Hartz Reforms: The Performance of Active Labour Market Policy in Germany", Journal for Labour Market Research, 2007, 40, pp.45-64.

[15]Local Data Base of Central Statistical Office in Poland (CSO) 2008-2014. [online] [01.02.2018] Available at: http://stat.gov.pl/bdl/

[16] RDIM. Regional data. [online] [28.08.2016]. Available at: http://raim.gov.lv/lv/riki

[17] Rural Support Service (RSP). Unpublished data.

[18] European Commission. Guidance note E - Measure Fiches. [online] [07.02.2018]. Availabel at: https://ec.europa.eu/agriculture/sites/agriculture/files/rural-development-previous/2007-

2013/docs/note_e_en.pdf

[19] Latvijas lauku attīstības programma 2007.-2013.gadam (LAP) (Latvian Rural Development Programme 2007-2013 (RDP)) (in Latvian). [online] [12.02.2018]. Available at: https://www.zm.gov.lv/public/files/CMS_Static_Page_Doc/00/00/00/69/57/LAP_2007213_versija_15_clean.pdf

[20] Ministry of Agriculture and Rural Development in Poland (MARD). 2017, Collective current report on the implementation of the Rural Development Programme 2007-2013 as at 31 December 2015. 